Original Research Article

\title{
The study of adverse drug reactions of antihypertensive medicines in essential hypertension patients in Hi-Tech Medical College and Hospital, Bhubaneswar, Odisha, India
}

\author{
Bikash Roy*, Srikanta Mohanty, Anju Prasad, Chaitali Pattanayak, \\ Ratna Palit, Ashok Singh Chouhan
}

Department of Pharmacology, Hi-Tech Medical College and Hospital (HMC \& H), Bhubaneswar (BBSR), Odisha, India

Received: 23 January 2019

Revised: 11 February 2019

Accepted: 06 April 2019

\section{*Correspondence to:}

Dr. Bikash Roy,

Email:pgph2016@gmail.com

Copyright: (C) the author(s), publisher and licensee Medip Academy. This is an openaccess article distributed under the terms of the Creative Commons Attribution NonCommercial License, which permits unrestricted noncommercial use, distribution, and reproduction in any medium, provided the original work is properly cited.

\begin{abstract}
Background: Every drug has the potentiality to cause an adverse drug reaction (ADR). ADRs are a major problem in drug therapy. The aim of this study was to assess the incidence and causality of ADRs to antihypertensive agents used for the essential hypertensive patients attending at the general medicine out patients departments of Hi-Tech Medical College and Hospital, Bhubaneswar Odisha, during the time period of November 2016 to October 2018.

Methods: This prospective-observational study was carried out in general medicine outpatient department of Hi-Tech Medical College and Hospital, Bhubaneswar, Odisha.

Results: Out of 254 patients, $78(30.71 \%)$ patients were developed ADRs to antihypertensive drugs. $51(65.38 \%)$ were female and $27(34.62 \%)$ were male. Calcium channel blockers were the commonest therapeutic class of antihypertensive drugs associated with ADRs $(n=50,64.10 \%)$. According to WHO causality assessment scale most of the ADRs were "probable" 41 (52.56\%), followed by "possible" $21(26.92 \%)$, unclassifiable $13(16.67 \%)$ and unlikely $3(3.85 \%)$.

Conclusions: The results of this study concluded that antihypertensive drugs able to induce the development of adverse drug reactions, which were significant cause of increase burden on health care system and decrease the quality of life, the health care professionals should take care about the rational use of antihypertensive agents. Thus, to minimize the incidence of adverse drug reaction and to increase the quality of life.
\end{abstract}

Keywords: Adverse drug reaction, Causality assessment, Essential hypertension

\section{INTRODUCTION}

The study of ADRs is the concern of the field known as pharmacovigilance. Pharmacovigilance is defined by the World Health Organization (WHO) as "The science and activities relating to the detection, assessment, understanding and prevention of adverse effects or any other possible drug-related problems". ${ }^{1}$ Drugs are double edged weapons, it provides innumerable benefits to patients, but improper administration of drugs can produce deleterious effect. ${ }^{2}$ An adverse drug reaction (ADR) is defined by the World Health Organization (WHO,1973) as a response to a drug which is noxious, unintended, and which occurs at doses normally used in man for the prophylaxis, diagnosis, or therapy of disease, or for the modification of physiological function. ${ }^{3}$

The majority of ADRs occur as a result of the extension of the desired pharmacologic effects of a drug, often due to the substantial variability in the pharmacokinetics and pharmacodynamics seen among patients. Every drug has the potentiality to cause an adverse drug reaction, but not 
all patients develop the same level and type of ADRs. Main factors that responsible for ADRs are- age, gender, dose, drug formulation, pharmacokinetic or pharmacodynamic abnormalities, drug interactions, immunology, genetics, ethnic variation, multiple drugs, disease state, past history of ADR or allergy. ${ }^{4}$ Adverse drug reactions (ADRs) are considered among the foremost causes of morbidity and mortality. The incidence of adverse drug reactions (ADR) varies with studies which show incidences ranging from as low as $0.15 \%$ to as high as $30 \% .^{3,5,6}$ Due to the limitation of pre- approval clinical trials, the complete adverse events profile of newly approved drugs is not reflected properly.

Classically, the most common dose related ADRs are usually detected in the pre-marketing phase of clinical trials for new drugs, as these trials are of short duration and are conducted in populations that number up to several thousands, while ADRs which are rare and those detected on long term use are not. The elderly persons, children, pregnant women, patients with multiple diseases, and those on medication suspected of interaction with the study drug are under exclusion criterion in most of the studies, so the study population does not reflect the true representation of the real world where the drug is eventually used. ${ }^{7}$

Hence, it is needless to say that there is crying need to monitor the safety profile of all the medications on continuous basis and to review their therapeutic rationale. Monitoring of ADRs is even more important in case of chronic ailments such as essential hypertension, which have the need of long term therapy predisposing to adverse drug events.

For the use of antihypertensive drugs in terms of rationality and safety, there is a need for a vivacious pharmacovigilance system at all the levels of health care. Hence, the development of a better system of reporting ADRs of drugs has been recommended as a paramount precedence action to preclude such ADRs in hospitals. Hospital based monitoring is one of the systems used to collect data on drug prescriptions and this data have become a central component of monitoring and evaluation activities performed in hospitals. ${ }^{8-10}$

So, the aim of this present prospective observational study was to determine the incidence and assessment of causality of ADRs of antihypertensive drugs occurring in patients of essential hypertension in the outpatient department of General Medicine ward of Hi-Tech Medical College and Hospital, Bhubaneswar, Odisha during the periods of November 2016-October 2018.

\section{METHODS}

This prospective, observational study was carried out between November 2016 to October 2018 in Medicine OPD of Hi-Tech Medical College and Hospital, Bhubaneswar, and Odisha. Patients attended in outdoor of general medicine ward of Hi-Tech Medical College and
Hospital, Bhubaneswar, Odisha, for the treatment of essential hypertension was taken for study for the period of November 2016 to October 2018. A total of 254 patients ( sample size $=254)$ prescription were collected during the study period, who were on antihypertensive therapy. The age range of the patients of both genders were between 18 to 65 years and secondary hypertension and pregnancy induced hypertension were the exclusion criteria. The study protocol was approved by the Institutional Ethics Committee (IHEC) for human research of $\mathrm{Hi}$-Tech Medical College and Hospital. An informed consent was taken from the patients, participating in the study. The quality of the data and its confidentiality were ensured by keeping the patients' identity coded with their initials only. Any information about any patient was kept strictly confidential and not shared with unauthorized individuals. The patient's right to confidentiality, information and privacy were respected.

\section{Statistical analysis}

Data were analyzed using SPSS (Statistical package for the Social Sciences, SPSS) with latest software version. Descriptive and inferential analyses were conducted as appropriate, and level of significance was set at $\mathrm{P}<0.05$. The association and causality assessment, between antihypertensive drugs and ADR were evaluated by using the WHO -UMC scale and Naranjo scale. ${ }^{11,12}$

\section{RESULTS}

Total number of 254 prescriptions were collected as per inclusion and exclusion criterion and 78 ADRs were also collected and analysed. In this study out of 254 patients, $172(67.72 \%)$ were male and $82(32.28 \%)$ were female (Table 1).

\section{Table 1: Gender wise distribution of the study} population.

\begin{tabular}{|lll|}
\hline Gender & Number of patients (\%) & P value \\
\hline Male & $172(67.72 \%)$ & P $<0.0001$ \\
\hline Female & $82(32.28 \%)$ & \\
\hline Total & $254(100 \%)$ & - \\
\hline
\end{tabular}

Table 2: Number of adverse drug reactions recorded.

\begin{tabular}{|l|l|l|}
\hline $\begin{array}{l}\text { Total number } \\
\text { of patients }\end{array}$ & $\begin{array}{l}\text { Development of } \\
\text { No. of ADRs }\end{array}$ & $\begin{array}{l}\text { Percentage } \\
(\%)\end{array}$ \\
\hline 254 & 78 & $30.71 \%$ \\
\hline
\end{tabular}

Males have shown higher prevalence of essential hypertension compared to female. There is highly significant association between essential hypertension and sex $(\mathrm{P}<0.0001)$, age ranged from 18 to 65 years with a Mean \pm SD (standard deviation) age of $48 . \pm 57.8$ years. There is highly significant association between essential hypertension and age ( $\mathrm{p}<0.0001)$. Among the 254 prescriptions of antihypertensive drugs. 178 (70.08\%) were 
on mono-therapy and $76(29.92 \%)$ were on combination therapy. Among the prescriptions of antihypertensive drugs as combination therapy, 54 (21.26\%), 22 (8.66\%) were combination of two $\&$ three drugs respectively.

In this study it was observed that $78(30.71 \%)$ ADRs were developed for different types of antihypertensive drugs during the period of 2 years from November 2016 to October 2018 (Table 2). The distribution of ADRs in male was $34.62 \%$, while in female, it was $65.38 \%$, which is statistically significant ( $\mathrm{p}<0.05$ ) (Figure 1).

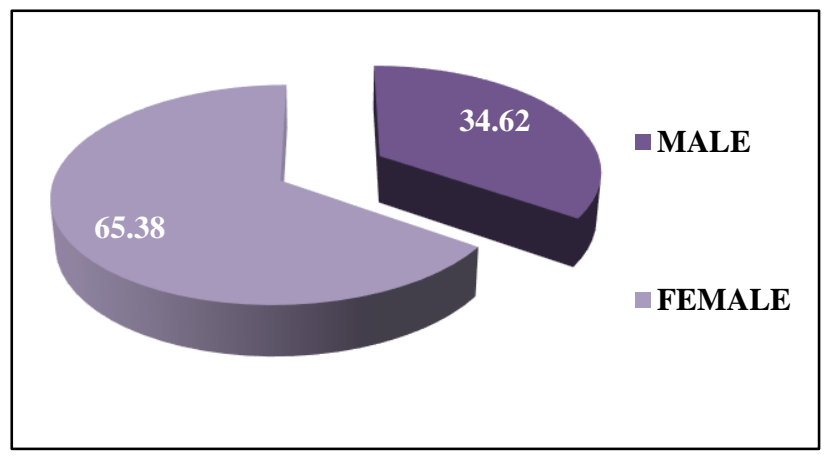

Figure 1: Gender distribution of patients developing ADRs to antihypertensive drugs.

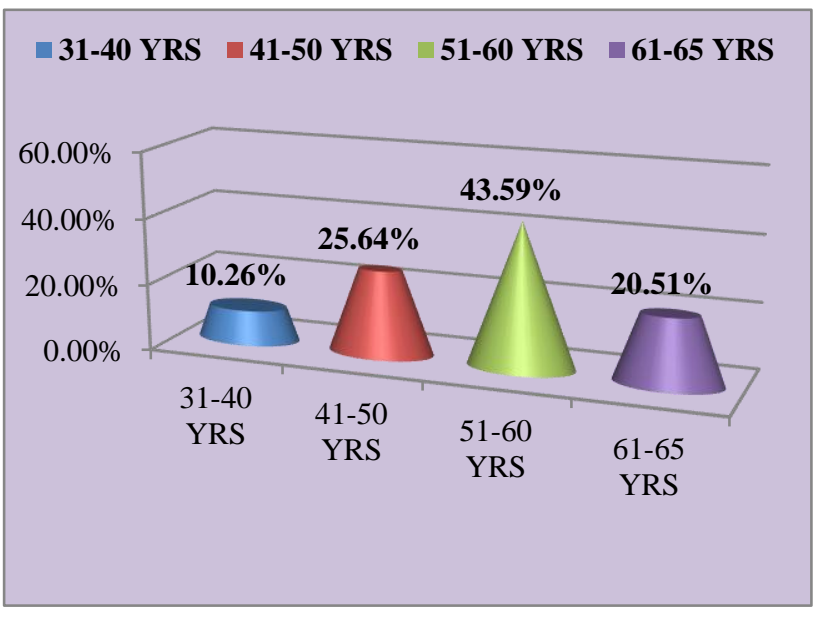

Figure 2: Age distribution of patients developing ADRs to antihypertensive drugs.

It was also observed that ADRs to antihypertensive drugs were most commonly in age group of 51-60 years, the number of ADRs in this age group were 34 (43.59\%). The number of patients developed ADRs in other age groups are $20(25.64 \%)$ in the age group $41-50 \mathrm{yrs}, 16(20.51 \%)$ in the age group of $61-65 \mathrm{yrs}$ and $8(10.26 \%)$ in the age group of 31-40 yrs as (Figure 2).

One of the important reflection of this study was that CCBs were the commonest therapeutic class of antihypertensive drugs associated with ADRs $(n=50,64.10 \%)$. Other groups associated with ADRs were ARBs $(\mathrm{n}=9,11.54 \%)$, $\beta$-blockers $(n=7,8.97 \%)$, ACE inhibitors $(n=8,10.26 \%)$ and diuretics $(\mathrm{n}=4,5.13 \%)$ (Table 3$)$.
Table 3: Distribution of ADRs on treatment with different classes of antihypertensive drugs.

\begin{tabular}{|ll|}
$\begin{array}{ll}\text { Class of drug associated with } \\
\text { ADRs }\end{array}$ & Number $(\%)$ \\
\hline CCB & $50(64.10 \%)$ \\
\hline ARB & $9(11.54 \%)$ \\
\hline$\beta$-Blockers & $7(8.97 \%)$ \\
\hline ACEI & $8(10.26 \%)$ \\
\hline Diuretics & $4(5.13 \%)$ \\
\hline Total & $78(100 \%)$ \\
\hline
\end{tabular}

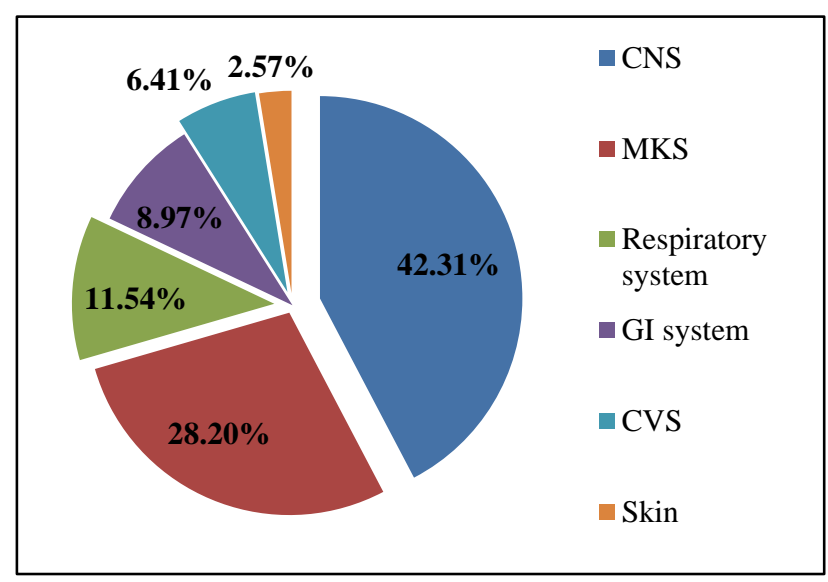

Figure 3: Distribution of ADRs to antihypertensive drugs affecting various systems.

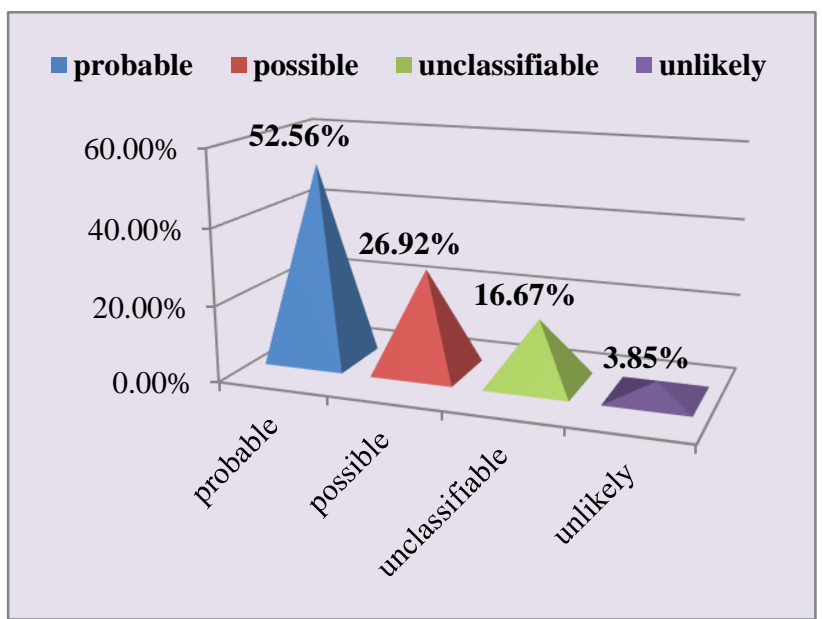

Figure 4: Distribution of ADRs according to WHO causality assessment scale.

Amlodipine was found to be the commonest drug associated with ADRs $(n=41,52.56 \%)$. In this study ADRs to antihypertensive drugs associated with central nervous system $(\mathrm{n}=33,42.31 \%)$ were found to be the most frequent (headache, dizziness, sedation). Other systems associated with ADRs were musculoskeletal system $(n=22$, $28.20 \%$ ) [pedal oedema, fatigue and muscle cramp], respiratory system $(\mathrm{n}=9,11.54 \%)$ [dry cough and breathlessness], gastrointestinal system $(\mathrm{n}=7,8.97 \%)$ [abdominal discomfort and diarrhoea], cardiovascular 
system $(n=5,6.41 \%)$ [bradycardia] and skin $(n=2,2.57 \%)$ [irritation all over the body] (Figure 3).

According to WHO causality assessment scale most of the ADRs were "probable" 41 (52.56\%), followed by "possible" 21 (26.92\%), unclassifiable 13 (16.67\%) and unlikely 3 (3.85\%) (Figure 4). According to Naranjo scale $58(74.36 \%)$ ADRs were "Possible", 20 (25.64\%) were "Probable" and none were "Definite" (Figure 5). In this outpatient-based study there were absence of serious adverse reactions as there were no deaths, hospitalizations, disabilities, or life-threatening events that required intervention to prevent permanent damage.

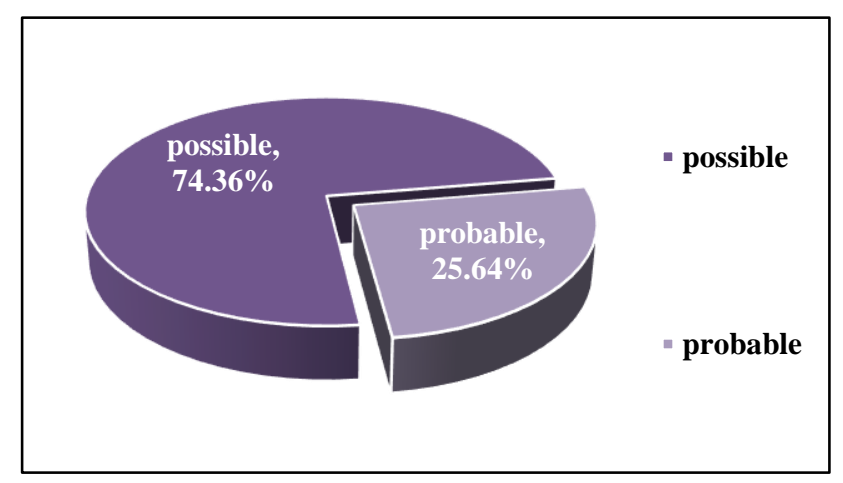

Figure 5: Distribution of ADRs according to Naranjo scale.

\section{DISCUSSION}

Adverse drug reactions adversely affect the health care system and quality of life of patients in many ways. The present study was conducted in order to identify and assess the ADRs occurred in the outpatient department of General Medicine ward of Hi-Tech Medical College and Hospital, Bhubaneswar, Odisha, during the time period of November 2016 to October 2018.

In this study $67.72 \%$ patients were male, and $32.28 \%$ patients were female, and it was found that essential hypertension was more prevalent in male than females. The hypothetical cause of higher number of male patients is due to the elevated levels of androgen (such as testosterone) as they play a significant role in elevation of blood pressure. ${ }^{13}$ This study was analogous to the studies conducted by Rackelhoff et al, and Nachiya et al. ${ }^{14,15}$

It was found that common age group of patients with essential hypertension was 51 to $60(51.18 \%)$ years. Plasma renin falls by $17 \%$ each decade which may be the possible reason of essential hypertension in advance age, this finding has already introduced a scorching question whether this renin is a friend or foe for the human beings. ${ }^{16}$ This study was similar to a study done by Tiwari et al, which also showed that the commonest age group affected was 51 to 60 years. ${ }^{17}$
This study showed that $70.08 \%$ of the patients had received monotherapy of antihypertensive drug which was similar to the study by Pai et al. ${ }^{18}$ But Etuk et al, showed that two drug combinations are commonly prescribed. ${ }^{19}$ This difference is commonly due to the doctor's choice of treatment taking into consideration of various factors like patient characteristics, presence of any comorbid conditions and the medicine availability. ${ }^{19}$

In the present study amlodipine was the most commonly used drug as monotherapy in $74.72 \%$ of patients. CCBs have very less or no metabolic effects which is beneficial for diabetic hypertensive patients and also it is cheap. These could be the reasons for it to be the most commonly prescribed drug. Drug utilization study of antihypertensive drugs by Maduram et al, and John et al, also showed amlodipine as the most frequently prescribed drug..$^{20,21}$ The antihypertensive effect of CCBs are independent of sodium intake or concurrent use of NSAIDS which is not the case with ACE inhibitors. In patients having hypertension with coexisting nephropathy, $\mathrm{CCBs}$ remarkably reduce the blood pressure. CCBs are the most preferred drugs in case of hypertensive patients with coexisting diabetes mellitus. They also have additional natriuretic effect and thus it rules out the need for adding a diuretic. ${ }^{22}$ One of the important factors which affects patient compliance and drug adherence is the occurrence of adverse drug reactions. In this study it was found that, out of 78 ADRs recorded, $65.38 \%$ were female and $34.62 \%$ were male. Theoretically women were thought to be at greater risk of adverse drug reactions than men, which might be due to gender related differences in pharmacokinetics, immunology and hormonal factors. Rational adjustment of dose will help to minimize ADRs in females.

In this study, the more number of ADRs were found $(43.59 \%)$ in age group of 51-60 years which was similar to the study by Solanki et al. ${ }^{23}$ It was found that elderly patients are more prone to ADRs than younger patients, most common system associated with ADRs was central nervous system; but Hussain et al, study reported cardiovascular system as the commonly affected system. ${ }^{24}$ In our study ADRs also involved musculoskeletal system, respiratory system, gastrointestinal system, cardiovascular system and skin. ${ }^{24}$ This study showed that different patterns of prescriptions of antihypertensive drugs produced different types of ADRs.

One of the important reflection of this study was, CCBs were the common group of antihypertensive drugs associated with ADRs (64.10\%) which was similar to the study by Basak et al. ${ }^{25}$ In CCBs, amlodipine was found to be the commonest drug associated with ADRs. The most common individual ADR was headache which was seen in $20.93 \%$ of the patients which was similar to the study done by Alomar et al. ${ }^{26}$ This could be due to arteriolar vasodilatation caused by CCBs. In present study peripheral oedema is also one of the common ADR seen with the use of CCBs. It occurs due to pre capillary dilation and reflex 
post capillary constriction causing increase in hydrostatic pressure. $^{22}$

This study showed that according to WHO causality assessment scale $52.56 \%$ of the ADRs were probable which means that these reactions were caused by the use of antihypertensive drugs and not due to any disease or by the use of other drugs and clinical improvement was seen when the drug was dechallenged. Possible ADRs were seen in $26.92 \%$ of the patients which could be due to presence of a disease or simultaneous use of other drugs.

The causality assessment by Naranjo scale showed that 74.36\% ADRs were Possible. Naranjo scale helps to determine whether ADR is due to the drug or due to other factors. A study done by Rende et al, showed a probable association in $92 \%$ and a possible association in $8 \% .^{27}$

In this study it was reflected that elderly individuals were at high risk of developing ADRs and most of the ADRs were preventable. Prescribing doctors should have sound knowledge regarding the basic pharmacology and how age affects pharmacokinetics of the drugs which will help to prevent various ADRs.

\section{CONCLUSION}

This prospective observational study was conducted at General Medicine OPD of Hi-Tech Medical college and Hospital, BBSR, ODISHA, during the period from November 2016 to October 2018 to find out and assess the incidence and causality of ADRs related to antihypertensive drugs. In this study the ADRs were found probable $(52.56 \%)$, possible $(26.92 \%)$, unclassifiable $(16.67 \%)$ and unlikely $(3.85 \%)$ by using WHO causality assessment scale.

By using Naranjo algorithm scale, it was found that ADRs were possible in $74.36 \%$ and probable in $25.64 \%$ of cases. This study also found that amlodipine was responsible for most of the ADRs and among all the ADRs reported headache was the commonest followed by dizziness, pedal oedema, fatigue, abdominal pain, dry cough, breathlessness, bradycardia, muscle cramps, sedation, diarrhoea and irritation all over the body. The results of this study would be useful for the physicians in rational selection of drug therapy for treatment of hypertensive patients. The present data suggest that the ADR monitoring needs to be done in hospital settings continuously so that untoward effect caused by different medicines can be identified and documented.

\section{ACKNOWLEDGEMENTS}

Authors express their humble thanks to all the respected Teachers and Professors of PG, Department Pharmacology and General Medicine and Respected Principal of Hi-Tech Medical College and Hospital Bhubaneswar, Odisha, India.
Funding: No funding sources

Conflict of interest: None declared

Ethical approval: The study was approved by the Institutional Ethics Committee [Ref. No. HMCH/IEC / PG / $16 / 3441(12)]$

\section{REFERENCES}

1. The Safety of medicines in public health programmes. Pharmacovigilance an essential tool. Geneva WHO. $2006 . \quad$ Available at: https://www.who.int/medicines/areas/quality_safety/s afety_efficacy/Pharmacovigilance_B.pdf. Accessed 10 January 2019.

2. Vora MB, Trivedi HR, Shah BK, Tripathi CB. Adverse drug reactions in inpatients of internal medicine wards at a tertiary care hospital: A prospective cohort study. J Pharmacol Pharmacotherapeut. 2011;2(1):21-5.

3. Lazarou J, Pomeranz BH, Corey PN. Incidence of adverse drug reactions in hospitalized patients: a metaanalysis of prospective studies. JAMA 1998;279(15):1200-5.

4. Alomar MJ. Factors affecting the development of adverse drug reactions. Saudi Pharmaceut J. 2014;22(2):83-94.

5. Beijer HJ, De Blaey CJ. Hospitalisations caused by adverse drug reactions (ADR): a meta-analysis of observational studies. Pharmacy World Sci. 2002;24(2):46-54.

6. Jose J, Rao PG. Pattern of adverse drug reactions notified by spontaneous reporting in an Indian tertiary care teaching hospital. Pharmacol Res. 2006;54(3):226-33.

7. Kennedy DL, Goldman SA, Lillie RB. Spontaneous reporting in the United States. In: Strom BL, editor. Pharmacoepidemiology. 3rd ed. Chichester: John Wiley and Sons, Ltd.; 2000:151-174.

8. de Araújo Lobo MG, Pinheiro SM, Castro JG, Momenté VG, Pranchevicius MC. Adverse drug reaction monitoring: support for pharmacovigilance at a tertiary care hospital in Northern Brazil. BMC Pharmacol Toxicol. 2013 Dec;14(1):5.

9. Patidar D, Rajput MS, Nirmal NP, Savitri W. Implementation and evaluation of adverse drug reaction monitoring system in a tertiary care teaching hospital in Mumbai, India. Interdisciplinary Toxicol. 2013 Mar 1;6(1):41-6.

10. Shrivastava M, Uchit G, Chakravarti A, Joshi G, Mahatme M, Chaudhari H. Adverse drug reactions reported in Indira Gandhi government medical college and hospital, Nagpur. J Assoc Physicians India. 2011;59:296-9.

11. Uppsala Monitoring Centre. The use of the World Health Organization-Uppsala Monitoring Centre (WHO-UMC) system for standardised case causality assessment. 2006. Available at: http://whoumc.org/graphics/4409.pdf.

12. Busto U, Naranjo CA, Sellers EM. Comparison of two recently published algorithms for assessing the 
probability of adverse drug reactions. Br J Clin Pharm. 1982;13: 223-7.

13. Svartberg J, von Muhlen D, Schirmer H, BarrettConnor E, Sundfjord J, et al. Association of endogenous testosterone with blood pressure and left ventricular mass in men. The Tromso Study. Eur J Endocrinol. 2004;150(1):65-71.

14. Reckelhoff JF. Gender differences in the regulation of blood pressure. Hypertension. 2001;37(5):1199-208.

15. Jainaf Nachiya RA, Parimalakrishnan S, Ramakrishna Rao M. Study on drug utilization pattern of antihypertensive medications on out-patients and inpatients in a tertiary care teaching hospital: A cross sectional Study. Afr J Pharmacy Pharmacol. 2015;9(11):383-96.

16. Brown MJ. Renin: friend or foe? Heart. 2007;93(9):1026-33.

17. Tiwari R, Bhardwaj A, Alam N, Dabas V, Sharma S. To evaluate the drug utilization pattern in patients using antihypertensive drug therapy. Asian J Biochem Pharm Res. 2012;2(1):425-33.

18. Pai PG, Shenoy J, Sanji N. Prescribing patterns of antihypertensive drugs in a South Indian tertiary care hospital. Drug Invention Today. 2011;3(4):38-40.

19. Etuk E, Isezuo SA, Chika A, Akuche J, Ali M. Prescription pattern of anti-hypertensive drugs in a tertiary health institution in Nigeria. Ann Afr Med. 2008;7(3):128-32.

20. Maduram A, Harikrishna - Prescription pattern of antihypertensive drugs in Shri Sathya Sai medical college \& research institute. Int J Basic Med Sci. 2013;4(2):68-72.

21. John LJ, Devi P, Guido S. Utilization of antihypertensive medications among the critically ill patients. RJPBCS. 2012;3(3):650-4.
22. Goodman \& Gilman's - The Pharmacological Basis of Therapeutics by- Laurence L. Brunton, RandaHilalDandan, Bjorn C. Knollmann- McGraw Hill Education, 13th ed.; 2017:489-526.

23. Solanki KC, Mistry RA, Singh AP, Jadav SP, Patel NM, Trivedi HR. Drug utilization study of antihypertensive drugs and their adverse effects in patients of a tertiary care hospital. J Clin Exp Res. 2013;1(3):58-67.

24. Hussain A, Aqil M, Alam MS, Khan MR, Kapur P, Pillai KK. A pharmacovigilance study of antihypertensive medicines at a South Delhi hospital. Indian J Pharm Sci. 2009;71(3):338-41.

25. Basak SC, Ravi K, Manavalan R, Sahoo K. A study of adverse drug reaction to antihypertensive drugs perceived by patients in a rural hospital. Indian $\mathbf{J}$ Pharm Sci. 2004;66(6):814-17.

26. Alomar MJ, Strauch CC. A prospective evaluation of antihypertensive medications safety and efficacy in United Arab Emirates private hospitals. Am J Pharmacol Toxicol. 2010;5(2):89-94.

27. Rende P, Paletta L, Gallelli G, Raffaele G, Natale V, Brissa N, et al. Retrospective evaluation of adverse drug reactions induced by antihypertensive treatment. J Pharmacol Pharmacother. 2013;4(1):S47-50.

Cite this article as: Roy B, Mohanty S, Prasad A, Pattanayak C, Palit R, Chouhan AS. The study of adverse drug reactions of antihypertensive medicines in essential hypertension patients in Hi-Tech Medical College, Bhubaneswar, Odisha, India. Int J Basic Clin Pharmacol 2019;8:886-91. 